\title{
GREEN SYNTHESIS AND CHARCTERIZATION OF ZnO NANOPARTICLES FROM LEAFS EXTRACTS OF ROSA INDICA AND ITS ANTIBACTERIAL ACTIVITY
}

\author{
Amrita Raj 1,*, and Reena Lawerence ${ }^{2}$ \\ 1,* Department of Chemistry,Sam Higginbottom University of Agriculture Technology \& \\ Science Allahabad, 211003, Uttar Pradesh, INDIA \\ ${ }^{2}$ Department of Chemistry, Sam Higginbottom University of Agriculture Technology \& Science, \\ Allahabad, 211003, Uttar Pradesh, INDIA \\ *E-mail: amrita15phchem104@gmail.com
}

\begin{abstract}
S
The present study was carried out to the green synthesis of $\mathrm{ZnO}$ nanoparticles and investigation of its antibacterial activity. Rosa indica leaves is of considerable interest and is a well-known compound because of its show antioxidant, antidiabetic, anti-inflammatory, antimicrobial activities etc . In the present study focuses on the Green synthesis of $\mathrm{ZnO}$ nanoparticles by sodium hydroxide, Zinc acetate and biocomponents of leaves of Rosa indica in the reaction mixture was observed in the precipitate from, which proved the formation of $\mathrm{ZnO}$ nanoparticles. Further, the green synthesized $\mathrm{ZnO}$ nanoparticles were characterized UV-Vis spectrophotometer, XRD analysis, FTIR, DLS, SEM with EDX. this all analysis shows the confirm the nanoparticles the ZnO nanoparticles show particles size $10 \mathrm{~nm}$ through DLS analysis. Antibacterial activity of the $\mathrm{ZnO}$ nanoparticles was evaluated by testing against Gram-negative(E.coli) and Gram-positive (S.aureus) bacteria. The antibacterial activity of the Synthesized $\mathrm{ZnO}$ nanoparticles was found to be more effective against Gram-positive bacteria (S.aureus).

Keywords: Green synthesis, Rosa indica, $\mathrm{ZnO}$ nanoparticles, SEM, UV-Vis spectrophotometer, XRD, Antibacterial activity.
\end{abstract}

(C) RASĀYAN. All rights reserved

\section{INTRODUCTION}

In recent years, nanotechnology has gained more attention and the research providing more innovation in many fields like electronics, drugs industry, Ceramic industry etc. ${ }^{1}$ Nowadays, we are witnessing the development and advancement of a new interdisciplinary scientific field nanoscience.As was shown by numerous example in physics, chemistry and biology, a transition from macro sizes to those of 1-100 nm gives size to qualitative change in physicochemical properties ${ }^{2}$ of individual compounds and system. The dependence of physicochemical properties on the particle size was magnetic properties, thermodynamics, electrochemistry, conductivity and electron transport. ${ }^{3}$ Nanochemistry or Nanotechnology related with the production and reactions of nanoparticles and their compounds.It is concerned with the unique properties associated with assemblies of atom or molecules on a scale between that of the individual building blocks and the bulk material (from 1 to 1000), At this level, the quantum effect can be significant, and also new ways of carrying out chemical reactions become possible. ${ }^{4-5}$ The science we methodologies from the synthetic chemistry and the material chemistry to obtain nanomaterial with specific size, shapes, surface properties.Cross-disciplinary nanoscience research involving physics, chemists and engineers are concerned about the need for developing eco-friendly and sustainable methods for the synthesis of nanomaterials. ${ }^{6}$ There are many methods for the synthesis of nanoparticles but one of the most conventional methods is green synthesis because it is an eco-friendly, non-toxic, very less expensive and very pure method. ${ }^{7}$ Nanoparticles having unique properties arising from their nanoscale dimensions. Nanoparticles have many important properties and various application in many areas such as a drug, food,

Rasayan J. Chem., 11(3), 1339-1348(2018)

http://dx.doi.org/10.31788/RJC.2018.1132009

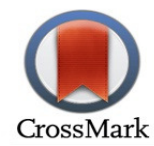


nutrition, electronics etc. ${ }^{8}$ The biological synthesis of nanoparticles which is very monodispersed particles with very specific sizes and shapes.

The huge application in the application in a pharmaceutical company for successful treatment as for disease. ${ }^{9-10}$ Green synthesis nanoparticles have great properties, which is synthesized by every part of a plant such as, root, leaf, stem, flower, bark etc. In Synthesis of nanoparticles dried from being used. ${ }^{11}$ Every plant hasterpenoids, alkaloids, Flavanoid, total phenolic content, which is a help to synthesized the nanoparticles. ${ }^{12}$ The most researchers studied nanoparticles . Today those nanoparticles are synthesized which are noble metals like silver, zinc oxide, gold, lead etc. But among the nanoparticles, ${ }^{13}$ zincoxidenanoparticles play an excellence role in the field of biological and drug industry. There is two type of approach for the synthesis of nanoparticles:

- Top-down approaches

- Bottom-up approaches

The very good effect shows a bottom-up approach as compared to top-down approaches. The bottom-up approaches show best results to produce the nanoparticles without any defects. The ZnO NPs having more advantages to inhibit the zone of inhibition. ${ }^{14-16}$

Their many potentials for human health.Biosynthesis of silver and zinc oxide nanoparticles by the plant, bacteria, fungi, and yeast. ${ }^{17}$ There are many routes for the synthesis of nanoparticles such as biological, chemical, physical, hydrothermal, electrochemical, irradiative, photochemical method. But green synthesis method has one of the best methods for the synthesis of nanoparticles. ${ }^{18-19}$

Rosa India is a traditional medicinal plant and its belong to the Rosaceae family. ${ }^{20}$ This plant has to show greatest advantages for a stomach problem, and are being an investigation for controlling cancer growth, constipation, inflammation, leucorrhea, heart and eye disease. Buds and Petal of Rosa indicia used for removal of gal bladder and kidney and flower are used against asthma. ${ }^{21}$ It is commonly cultivated for fiber and most edible purposes and many used for medicinal purposes. The plant has more medicine value show like antioxidant, blood pressure, antidepression, anticancer, diuretic, antifungal, anti-inflammatory, anti-carcinogenic activity.

\section{Materials}

\section{EXPERIMENTAL}

\section{Plant collection}

Medicinal and fresh leaves of Rosa indica were collected from Department of Horticulture, SHUATS Allahabad (State University), India.

\section{Chemicals}

Zinc acetate dihydrate (99.5\% purity) was obtained from $\mathrm{CDH}$ company, $\mathrm{NaOH}(99 \%$ pure pellet) obtained from Otto, biochemika company and all chemical analytical reagent grade. Ultra-purified water used throughout the research work to prepare a solution from a Merkmillipore-Milli-Q water purification System. All glassware have been washed with sterile double distilled water and dried in an oven before use.

\section{Preparation of plant extract}

$\mathrm{ZnO}$ nanoparticles were synthesized according to the method ${ }^{22}$ with slight modification.Rosa indica leaves were washed thoroughly under running deionized water and then rinsed thoroughly with ultrapurified water and dried at room temperature. Then the leaves are ground to make a fine powder and used for experimental studies. The solution of leaf broth was prepared by taking $20 \mathrm{~g}$ leaves powder in a 100 $\mathrm{ml}$ ultra-purified water (deionized water) and then boiling $60 \mathrm{~min}$ in the temperature at $70^{\circ} \mathrm{C}$.After that then the leafs broth was cool at room temperature then the leaf broth was filtered using Whatman filter paper and again leafs broth filtered by vacuum filter with $0.2 \mu \mathrm{m}$ pore size then leaf broth centrifuge at $3000 \mathrm{rpm}$ for $10 \mathrm{~min}$ for removing heavy metal and then leaf broth kept in a refrigerator at $4^{0} \mathrm{C}$ for further experimental use.

\section{Phytochemical Analysis ${ }^{22-23}$}

Phytochemical analysis of leaves extracts of Rosa indica ananlysis by UV-Vis spectrophotometer and FTIR . 


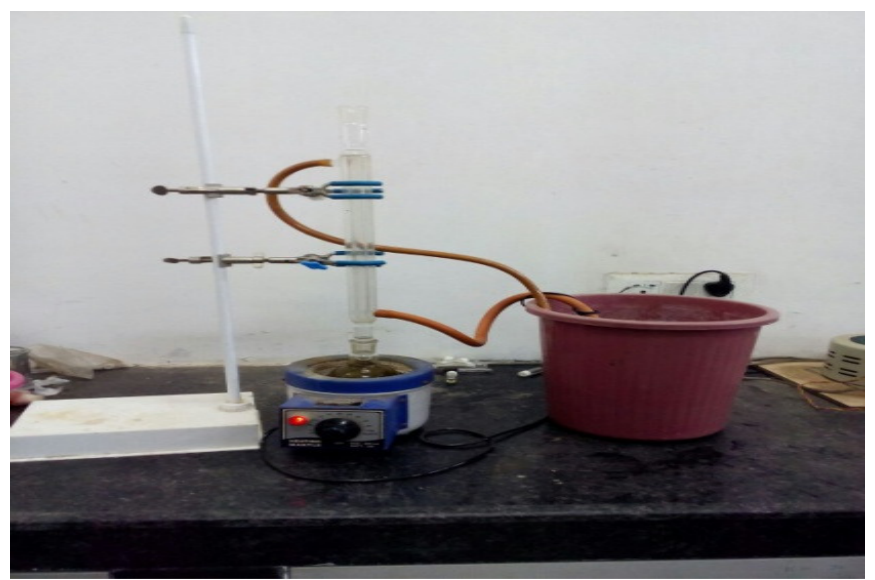

Fig.-1: Preparation of Plant Extract

\section{Green Synthesis of $\mathrm{ZnO}$ Nanoparticles ${ }^{22}$}

$10 \mathrm{ml}$ of the plant extract was heated at $60^{\circ} \mathrm{C}$ for $30 \mathrm{~min}$ and $20 \mathrm{ml}$ of a $2 \mathrm{mM}$ solution of zinc acetate solution was added dropwise to it under a magnetic stirrer for $30 \mathrm{~min}$. then $1 \mathrm{mM}$ solution of $\mathrm{NaOH}$ was added drop wise with the help of burette, when the $\mathrm{pH}$ adjusts 12 under constant magnetic stirrer. The reaction mixture shows a pale yellow color precipitate was obtained. For the precipitate was separated, the reaction mixture was centrifuged at $15000 \mathrm{rpm}$ for $15 \mathrm{~min}$. the precipitate was collected then dried in a muffle furnace at $60^{\circ} \mathrm{C}$. then the precipitate was stored for further studies. the precipitate was stored for further studies.

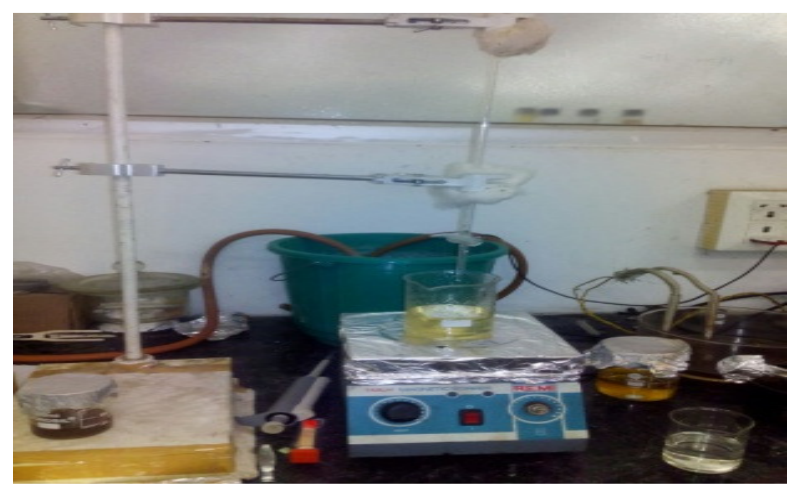

Fig.-2:Set up of Green Synthesis of ZnO Nanoparticles

\section{Characterization of Silver Nanoparticles}

UV-Vis Spectrophotometer

UV-Vis spectroscopic studies were carried out on a Shimadzu UV-3600 Plus spectrophotometer at MNNIT ALLAHABAD.

\section{Dynamic Light Scattering}

The average particle size of the synthesized silver nanoparticles was evaluated with the help of a Nano Microtrac total solution in particles at MNNIT ALLAHABAD.

\section{X-Ray Diffraction}

Silver nanoparticles were examined by X-Ray diffraction analysis using Rigaku Smart Lab X-ray diffractometer with $\mathrm{Cu} \mathrm{K} \alpha$ radiation monochromatic filter in the range of 10-90 at MNNIT Allahabad.

\section{Fourier Transform- Infra Red}

FTIR spectra of silver nanoparticles were recorded by Perkin Elmer Spectrum Version 10.4.00. at MNIT Jaipur. 


\title{
Scanning Electron Microscopy with EDX
}

SEM study was carried out to investigate the shape, size, and the surface area of the silver nanoparticles by ZEISS at IIT KANPUR.

\begin{abstract}
Anti-Bacterial Assay ${ }^{24}$
Anti-bacterial activities were studied against E.coli(MTCC 433) and S.aureus(MTCC 3160) strain. The antibacterial activity of Green synthesized $\mathrm{ZnO}$ nanoparticles was tested against positive and negative bacteria by the agar well diffusion method. To examine the antibacterial activity of Green synthesised $\mathrm{ZnO}$ NPs Muller- Hinton agar plates were sterilized and allowed to solidify. After solidification, 10 $\mu 1$ of each bacterial suspension was inoculated on the Petri plates by a sterile glass rod.Then ,using sterile borer punched four well into agar plates. Then we take three concentration, $25 \mu 1,50 \mu 1,75 \mu 1$ of $\mathrm{ZnO}$ nanoparticles was poured into well by the using of the micropipette. Then we take a control (Amoxicillin) and the concentration of control is $25 \mu \mathrm{l}$, which is poured in one well of the agar plates. After that incubated for $24 \mathrm{hrs}$ and at $37^{\circ} \mathrm{C}$, The were observed around the discs. Antibacterial activity was an investigation by measuring the diameter of the zones of inhibition .
\end{abstract}

\section{Statistical Analysis}

The antibacterial activity data were analyzed using ANOVA.

\section{RESULTS AND DISCUSSION}

In this result the first picture of leaves of Rosa indica, another picture is powder form of leaves of Rosa indica, leaves extracts of Rosa indica and last picture is Green synthesized ZnO NPs.

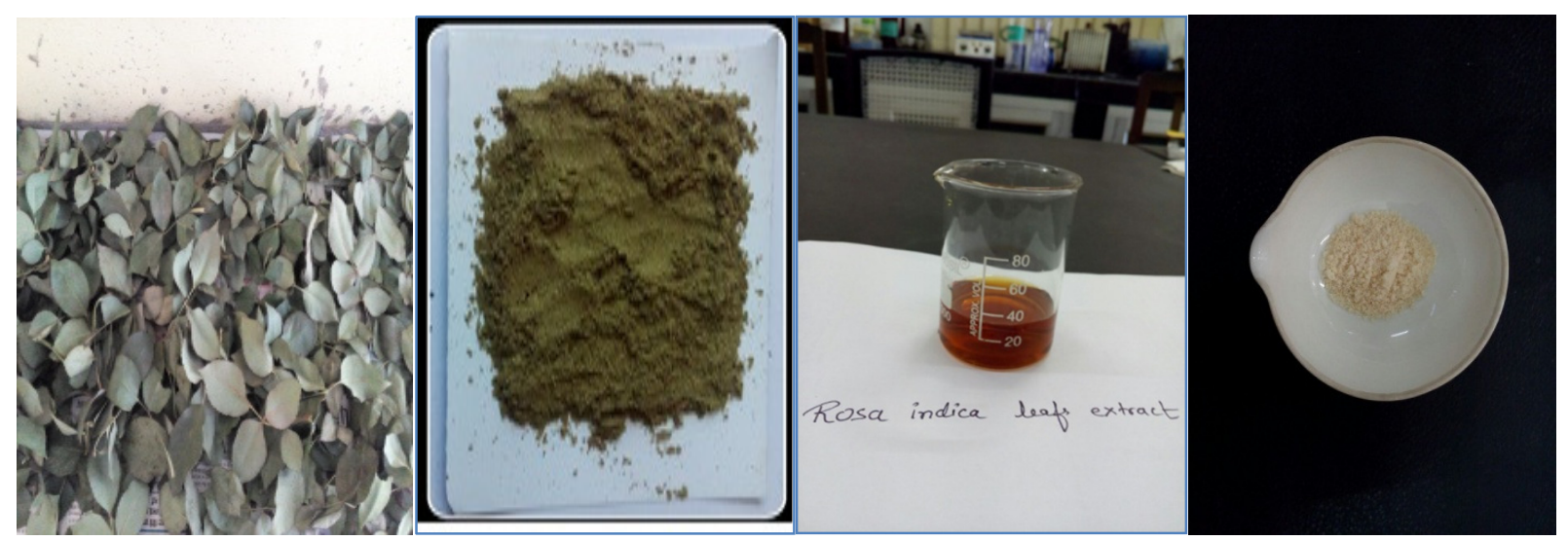

Fig.-3: (A) Leaves of Rosa indica, (B) Powder from of Leaves of Rosa indica,(C) Leaves Extracts of Rosa indica (D) Green Synthesized ZnO NPs.

\section{Phytochemical Analysis of Leafs Extracts}

The phytochemical analysis of leaves extract was examined spectroscopically. Phytochemical analysis of leafs broths was confirmed by the instruments of UV-Vis Spectroscopy and FTIR. It is given confirmation that total phenolic group, antioxidant content, flavonoids, amines etc. formed in the plant extracts, these compounds confirm by IR band which is used to as capping agent for the reduction of Zinc ion to $\mathrm{ZnO}$ nanoparticles.shown in Fig.-2(A) and 3(B) .The UV-Vis spectroscopy confirms the presence of polyphenol in the leaf extracts. The absorbance of leafs extracts presented peak at $270 \mathrm{~nm}$ as characteristic of polyphenol molecules. This result also according to the reported literature ${ }^{22}$ In FTIR Showing different functional groups in leaves extracts, that confirm the polyphenol groups present in plant extracts. ${ }^{22} \mathrm{Also}$, this result is according to reported literature. ${ }^{23}$

\section{UV-Vis Spectrophotometer}

The green synthesis of ZnO NPs was confirmation by the UV-Vis spectrophotometer.In UV-Vis spectrophotometer the range 300-800 in Fig.-1 and 200-800 fig; B. The ZnO NPs was show surface 
plasma resonance peak at $345 \mathrm{~nm}$, this peak shows the stability and confirmation of ZnO NPs Fig. A. In Zinc acetate solution showed no absorption peak , and In-Plant extract show absorbance peak at 320nm, $285 \mathrm{~nm}, 215 \mathrm{~nm}$, these peaks show polyphenol compounds and proteins present. A similar result is approximately reported result with slight modification. ${ }^{23}$
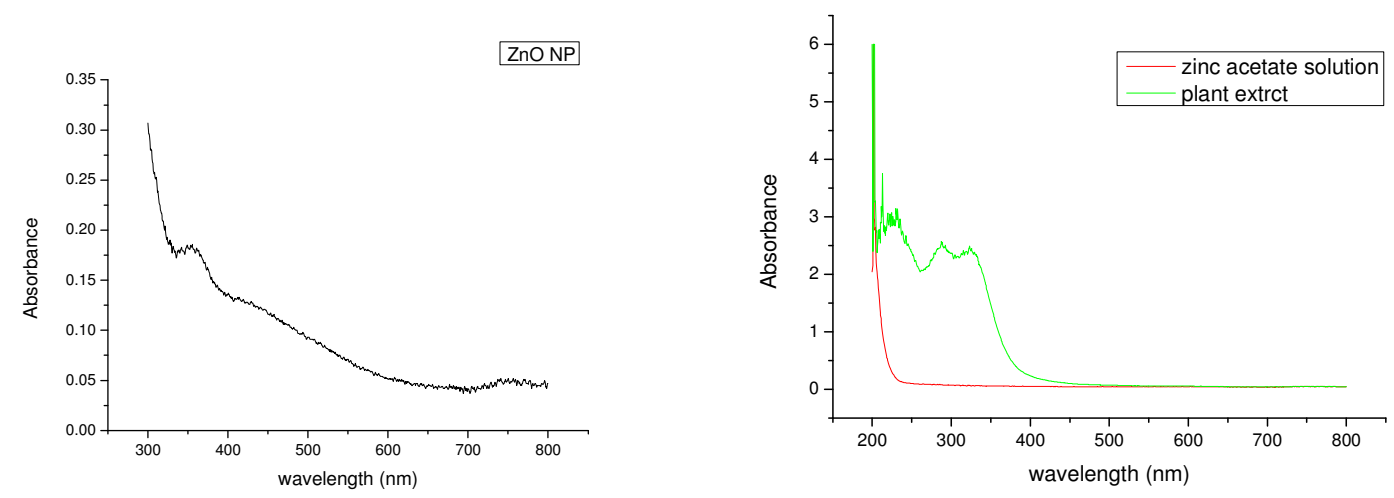

$(\mathrm{A})(\mathrm{B})$

Fig.-4: UV-Vis Spectrophotometer of Green Synthesized(A) ZnONPs, (B) Plant extracts and Zinc acetate solution

\section{X-Ray Diffractometer}

The green synthesis of ZnO NPs was confirmed by XRD analysis. The XRD peaks were identified as (100), (002), (101),(102), (110), (103), (200), (112), (201), (004) and (202), these peaks give confirmation and information of $\mathrm{ZnO}$ NPs. In this spectra show a highly strong peak and nature of zinc oxide nanoparticles.

The ZnO NPs size was obtained by Debye- Scherrer's formula :

Where:

$$
\mathrm{D}=\mathrm{K} \lambda /(\beta \cos \theta)
$$

$\mathrm{D}$ - the crystal size $(\lambda=0.15406 \mathrm{~nm})$ for $\mathrm{CuKa}$,

$\lambda$ - the wavelength of the $\mathrm{x}$-ray radiation

K- usually taken as 0.89

B- the line width at half- maximum height

In XRD analysis showing structural peaks and the approximate size of crystalline of nanoparticles around $35 \mathrm{~nm}$. The green synthesis of $\mathrm{ZnO}$ nanoparticles shows nanocrystalline in nature.

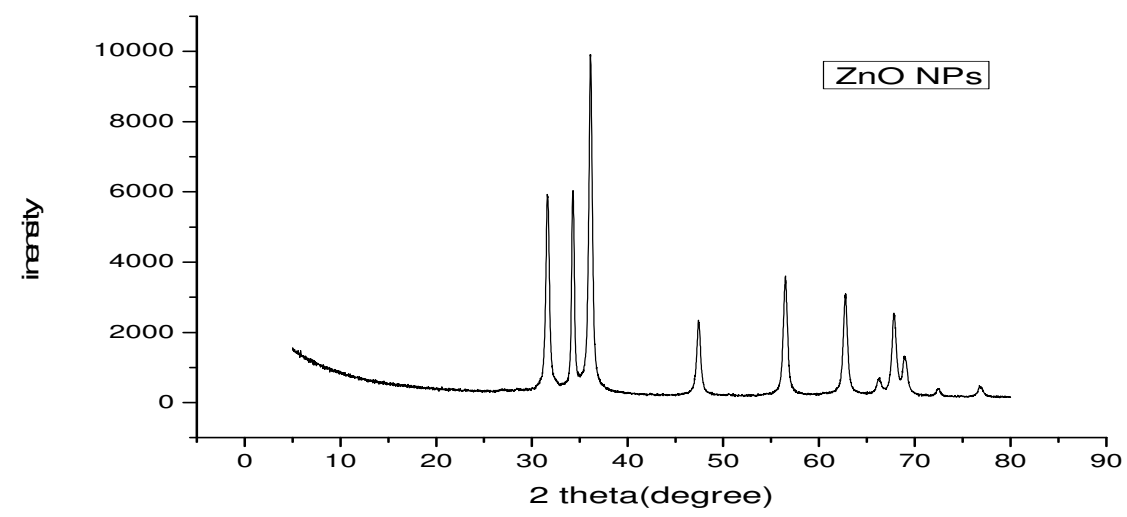

\section{FTIR Analysis}

Fig.-5: XRD Shows the Confirmation of ZnO NPs

The result was further confirmed by FTIR analysis .In FTIR spectra of leafs extracts indicate the presence of various functional groups, which are responsible for green synthesized ZnO NPs. The leaves extract act as a capping and stabilizing agents. In FTIR spectra indicate of various characteristic bands for various 
RASĀYAN $J$. Chem.

Vol. 11 | No. 3 |1339 - 1348 | July - September | 2018

functional groups in plant extract and green synthesis of ZnO NPs. In FTIR spectra observed that the bands are at $3184 \mathrm{~cm}-1,2465 \mathrm{~cm}^{-1}, 2273 \mathrm{~cm}^{-1}, 1646 \mathrm{~cm}^{-1}, 1548 \mathrm{~cm}^{-1}, 1384 \mathrm{~cm}^{-1}, 1019 \mathrm{~cm}^{-1}, 864 \mathrm{~cm}-1,572 \mathrm{~cm}^{-}$ ${ }^{1}, 443 \mathrm{~cm}^{-1}$. The spectrum of ZnO NPs was recorded in the range of $4000-500 \mathrm{~cm}-1$. The band formed at $572 \mathrm{~cm}^{-1}$ is indicated to $\mathrm{ZnO}$ stretching vibration. The band formed at $443 \mathrm{~cm}-1$ is indicated the presence of $\mathrm{ZnO}$ NPs.Aromatics compounds were formed and indicate by $\mathrm{C}=\mathrm{C}-\mathrm{C}$, a symmetric stretch of $-\mathrm{C}-\mathrm{C}=\mathrm{C}$ and $\mathrm{C}=\mathrm{C}$ was observed at around $1384 \mathrm{~cm}^{-1}, 1019 \mathrm{~cm}^{-1}, 1548 \mathrm{~cm}^{-1}$ and $1646 \mathrm{~cm}^{-1}$. The alcoholic groups $-\mathrm{C}$ $\mathrm{OH}, \mathrm{NH}_{2}$ show due to the bending vibration, secondary amine show due to stretching vibration and the band formed at $2465 \mathrm{~cm}^{-1}, 2273 \mathrm{~cm}^{-1}, 1646 \mathrm{~cm}^{-1}$ show due to $-\mathrm{C}=\mathrm{O}$ groups from the conjugation in the aromatic ring. The strong band at $1548 \mathrm{~cm}^{-1}$ and $1384 \mathrm{~cm}^{-1}$ was observed due to the glycosidic linkage of $\mathrm{C}-\mathrm{O}-\mathrm{C}$ and secondary alcoholic groups. ${ }^{28}$ The leaves extract having a large amount of phenolic compounds, flavonoids, amines, antioxidant, these groups are responsible for the stabilization and synthesis of zinc oxide nanoparticles.
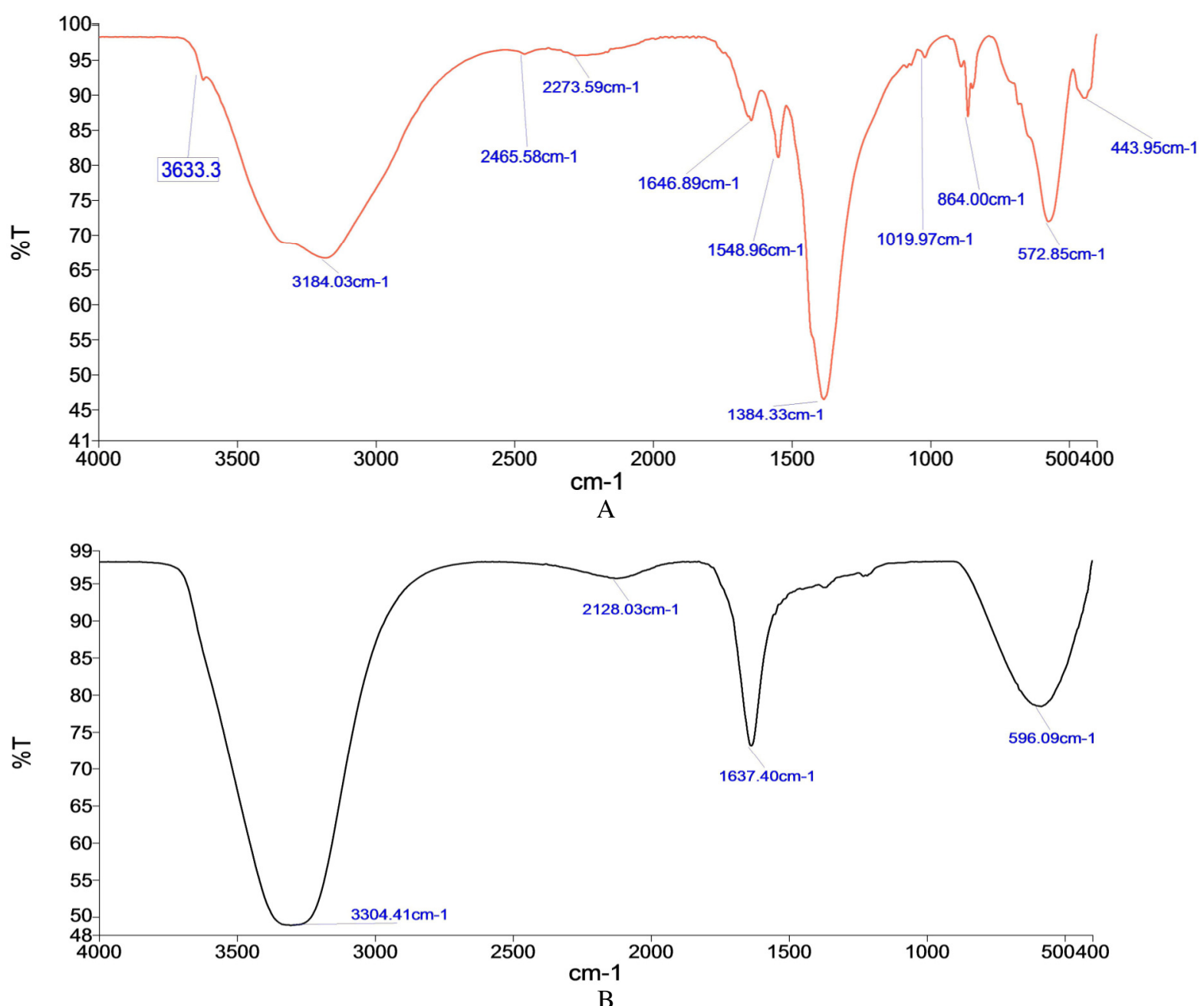

Fig.-6: FTIR Spectra (A) Silver Nanoparticles, (B) Leaves Extracts

\section{Scanning Electron Microscopy with EDX}

The surface morphology of the ZnO NPs was studied using scanning electron microscopy. This SEM Image showing the surface morphology of $\mathrm{ZnO}$ NPs. The solution of green synthesised of $\mathrm{ZnO}$ nanoparticles was formed by centrifuged at $15000 \mathrm{rpm}$ at $25 \mathrm{~min}$, then the suspension and pellet have separated the pellets again redispersed in ultrafine deionized water. The highly pure pellet was freeze then dried, then used for analysis. The surface morphology of silver nanoparticles was analyzed using scanning electron microscopy with EDX. This figure shows the confirmation of $\mathrm{ZnO}$ nanoparticles, which 
RASĀYAN $J$. Chem.

Vol. 11 | No. 3 |1339 - 1348 | July - September | 2018

is synthesized by leafs extracts. The green synthesized $\mathrm{ZnO}$ nanoparticles were small amount agglomerated. The green synthesis of $\mathrm{ZnO}$ nanoparticles is spherical in shape ${ }^{36} \mathrm{ZnO}$ nanoparticles were further confirmation by EDX. In EDX figure showing a strong peak which is indicating confirmation of $\mathrm{ZnO}$ NPs. The elemental composition of Zinc and oxygen was Formed in green synthesis of ZnO NPs was confirmed by the energy dispersive X-ray analysis. 23.5 weight percentage of oxygen and 78.4 weight percentage of Zinc was obtained in the analysis. ${ }^{29} \mathrm{~A} 62.45$ weight percentage of Zinc and 28.68 weight percentage of oxygen was reported and the most similar result reported. In this spectra, the $\mathrm{ZnO}$ NPs as products are formed.
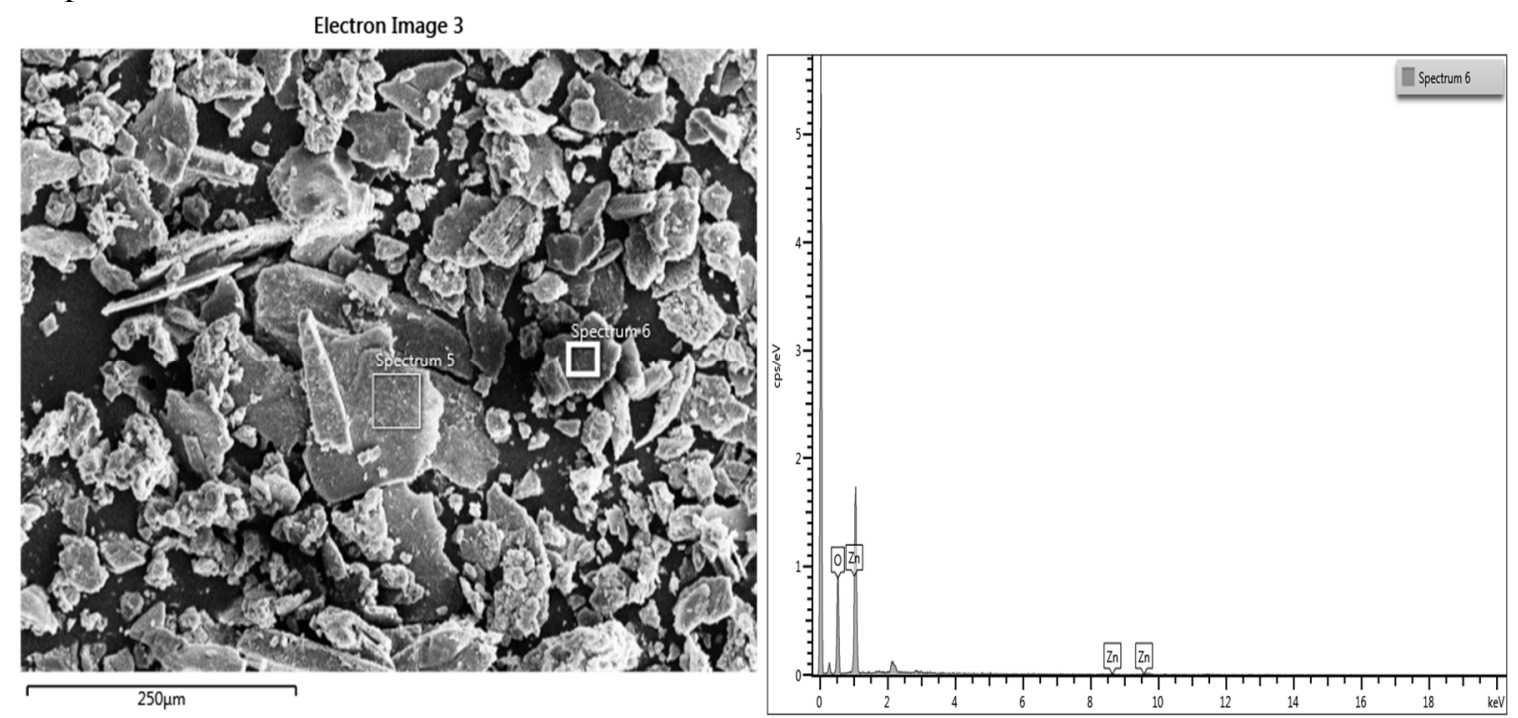

Fig.-7: Scanning Electron Microscopy with EDX

\section{Dynamic Light Scattering (DLS)}

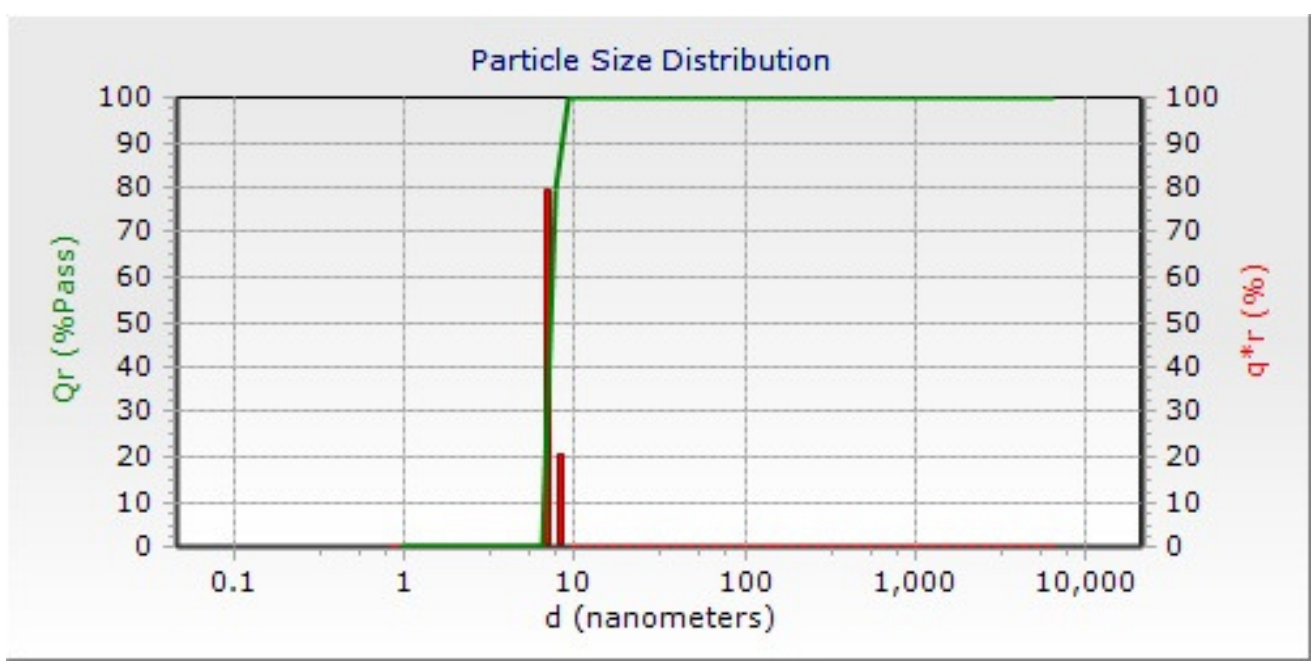

Fig.-8: Showing Particles Size Distribution of Green Synthesized Nanoparticles

In Dynamic light scattering used suspension of $\mathrm{ZnO}$ nanoparticles green synthesis from leaf extract from Rosa indica. The particle size distribution though the DLS indicates the size of green synthesized nanoparticles around10nm. the green synthesized ZnOnanoparticles are not agglomerated showing in Fog.-5.

\section{Antimicrobial Activity}

Antimicrobial activity was done by well diffusion method. The antimicrobial activity of Green synthesized $\mathrm{ZnO}$ NPs has accomplished against gram-positive and gram-negative bacteria. The green 
synthesized $\mathrm{ZnO}$ nanoparticles having excellent antimicrobial activity against gram-positive and gram negative bacteria. In this paper, the gram-positive bacteria indicating the highest zone of inhibition and most effective as compared to gram-negative bacteria. ${ }^{30}$ The highest zone of inhibition was observed for $15 \mathrm{~mm}$ in S.aureus and $14.5 \mathrm{in}$ E.coli at the highest concentration of $7.5 \mu \mathrm{g} / \mu \mathrm{l}$. According to figure $25 \mu \mathrm{l}$ concentration of amoxicillin showed the maximum radius of the zone of inhibition of 21 against S.aureusand 22.5 against E.coli. $\mathrm{ZnO}$ nanoparticles have shown most efficiency to inhibit the bacteria growth by the formation of reactive oxygen species ${ }^{31-32}$ and accumulation of nanoparticles. $\mathrm{ZnO}$ nanoparticles act as bactericidal and bacteriostatic agents.

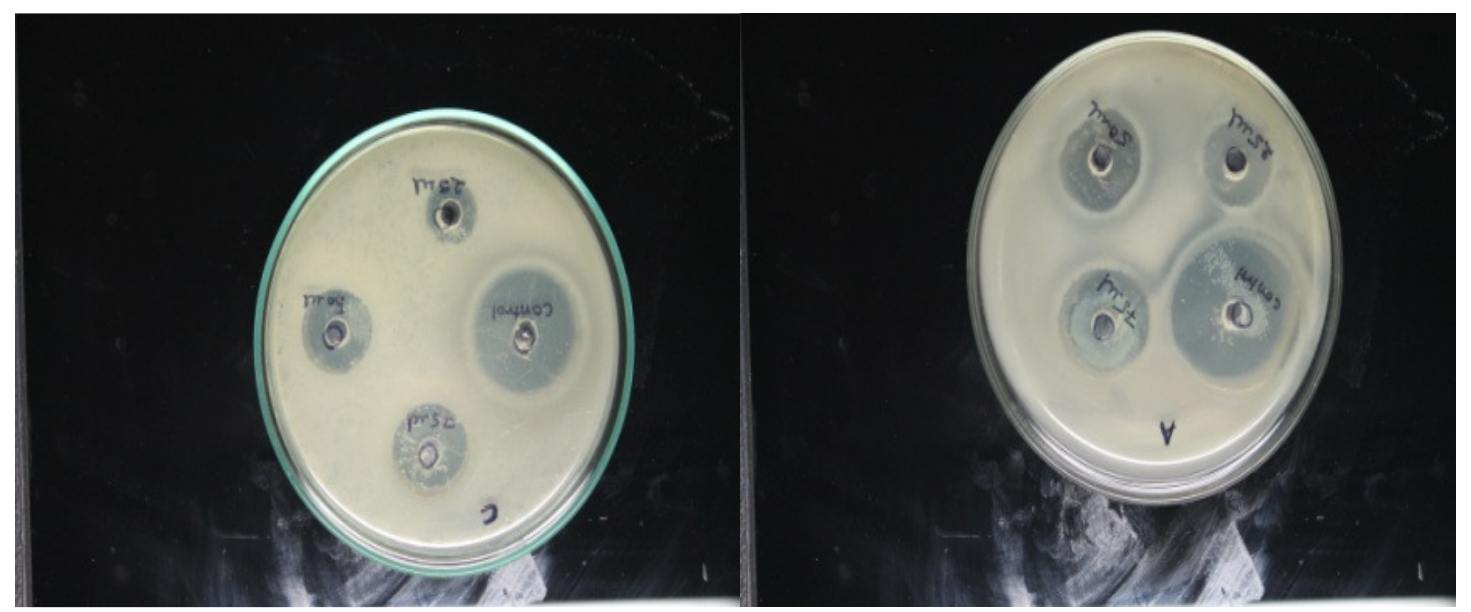

S.aureusE.coli

Fig.-9: Antibacterial Activity of ZnO Nanoparticles SynthesiedAgainstS.aureusand E.coli

Table-1: Zone of Inhibition (mm) obtained from well Diffusion Methods

\begin{tabular}{c|c|c}
\hline \multirow{2}{*}{$\begin{array}{c}\text { Concentrations } \\
\mu \mathrm{g} / \mu \mathrm{l}\end{array}$} & E.coli & Sone of inhibition $(\mathrm{mm})$ \\
\cline { 2 - 3 } & 8.3 & 9 \\
\hline 2.5 & 13.5 & 14 \\
\hline 5.0 & 13.8 & 14.9 \\
\hline 7.5 & $\mathrm{~S}$ & $\mathrm{~S}$ \\
\hline Result & 0.216 & 0.446 \\
\hline S. ED $( \pm)$ & 0.176 & 0.364 \\
\hline C.D at 5\% & & \\
\hline
\end{tabular}

\section{CONCLUSION}

In this paper, we study the Green synthesis of $\mathrm{ZnO}$ nanoparticles from leaves of Rosa indica. In this reaction leafs extracts used as a capping agent for the stability of nanoparticles. $\mathrm{ZnO}$ nanoparticles having spherical shape and size of $10 \mathrm{~nm}$.its show excellent antibacterial activity against gram-positive and gram-negative bacteria. Also, we confirmation of green synthesized $\mathrm{ZnO}$ nanoparticles by UV-Vis, XRD, DLS, FTIR, SEM, EDX. This is an eco-friendly, non-toxic, very conventional method.

\section{ACKNOWLEDGMENT}

This authors wish to thanks MNNIT and SHUATSAllahabad for financial support and having given feasibilities to carry out the research work.

\section{REFERENCES}

1. S.R. Senthilkumar and T. Sivakumar, International Journal of Pharmacy and Pharmaceutical Science., 6, 461(2014), DOI: 10.1080/23312009.2018.1469207

2. R. S. Devi and R. Gayathri, International Journal of Current Engineering and Technology, 4, 2347 (2014) , DOI: 10.1016/j.arabjc.2016.04.014 


\section{RASĀYAN J. Chem.}

Vol. 11 | No. 3 |1339 - 1348 | July - September | 2018

3. E. Elsayed, H. Hafez, S. Hassan, M.F. Elkady and E. Salama., International Journal of Scientific \& Technology Research., 3(9), 2277(2014), DOI: 10.1016/j.reffit.2016.06.003

4. S.Nagarajan and K.A.Kuppusamy, Journal of Nanobiotechnology, 11, 3 (2013) , DOI: 10.1186/14773155-11-39

5. E. Varghese and M. George, International Journal of Advance Research In Science And Engineering, 4, 30 (2015) , DOI:10.1016/j.jmst.2013.02.002

6. V. Pandiyarasan, P. Shanmugapriya, M. Y. Thanuja, T. Anusuya and P. Vairavaraja, Asian J. of Adv. Basic Sci, 3, 94(2014), DOI:10.1016/j.colsurfb.2014.11.025

7. M. Ayeshamariam, M. Kashif andV. S. Vidhya Journal of Optoelectronics and Biomedical Materials, 6(3), 85(2014), DOI: 10.1016/j.colsurfb.2014.11.025

8. G. Bhumi and N. Savithramma, Int. J. Drug Dev. \& Res., 6(1), I0975(2014), DOI: 10.1016/j.colsurfa.2013.09.034

9. S. Divyapriya, C.Sowmia, and S. Sasikala, World Journal of Pharmacy and Pharmaceutical Sciences, 3(12), 1635(2014), DOI: 10.1016/J.Saa.2014.09.118

10. M.S. Shekhawat, C.P. Ravindranand and M. Manokari, An Internstional Journal Society for Tropical Plant Research, 1(2),55(2014), DOI: 10.1016/J.Saa.2014.09.118

11. P. Ramesh, A. Rajendran, and Arumugam Subramanian, Asian Journal of Phytomedicine and Clinical Research. 2(4),189(2014), DOI: 10.1016/j.colsurfb.2010.05.024

12. R. Rajendran, C. Balakumar, Hasabo A. Mohammed Ahammed, S. Jayakumar, K. Vaideki and E.M. Rajesh., International Journal of Engineering, Science and Technology 2(1),202(2010), DOI: 10.1016/j.colsurfb.2010.05.024

13. A. H. Wani and M. A. Shah, Journal of Applied Pharmaceutical Science, 2(3), 40(2012), DOI: 10.1007/s11051-009-9835-3

14. A. Becherz, M. Du, P. L. Nostro and P. Baglioni., J. Nanopart. Res., 10, 679(2008), DOI: 10.1007/s11051-007-9318-3

15. C. Jayaseelana, A. A. Rahumana, A. V. Kirthi, S. Marimuthua, T. Santhoshkumara, A. Bagavana, K. Gauravb, L. Karthikb and K.V. Bhaskara SpectrochimicaActa Part A: Molecular and Biomolecular Spectroscopy, 90 78(2012), DOI: 10.1016/j.saa.2012.01.006. Epub 2012 Jan 9.

16. S. Sabir,M. Arshad, and S. K. Chaudhari., Hindawi Publishing Corporation, 8 (2014), DOI: $10.1155 / 2014 / 925494$

17. L. Zhang, Y. Ding, M. Povey and D. York, International Research Journal of Biological Sciences 18, 939(2008), DOI: 10.1016/j.pnsc.2008.01.026

18. H. A. Salam, P.Rajiv, M Kamaraj, P. Jagadeeswaran S. Gunalan and R. Sivaraj., Res. J. Biological Sci. 1, 5, 85(2012) , DOI: 10.1016/j.indcrop.2012.04.017

19. A. Tayel, F. Wael, S. A. Hodamahrous and M. F. Salem, Journal of Food Safety, 31, 211(2011), DOI: $10.1111 / \mathrm{j} .1745-4565.2010 .00287$.

20. Y. Liu1, L. He, A. Mustapha1, H. Li, Z.Q. Hu and M. Lin., Journal of Applied Microbiology 107, 4,1193(2009), DOI: 10.1111/J.1365-2672.2009.04303.X

21. R. P. Mishra and M. Arshad, JPBMS, 12, 15 (2011), DOI: 10.1016/J.Micron.2013.10.006

22. S. Niranjan, M. Saha, M. Charaborty, M.Maiti., S.Das., R.Basu and P Nandy, RSC Advance 5, 4993 (2015) , DOI: 10.1021/ie3001869

23. P.E. Ochieng, E. Iwuoha, I. Masikini, J. Ondiek, P. Githiraand and G. N. Kamau, International Journal of Biochemiphysics, 23, (2015), DOI: 10.1016/j.colsurfb.2009.06.005

24. Y. Xie, Y. He, L. P. Irwin, T. Jin and S, Xianming, Appl. Environ. Microbiol., 77(7), 2325(2011), DOI: 10.1128/AEM.02149-10

25. N. Jones, B. Ray, T. Koodali and C. A. Manna., FEMS Microbiology Letters, 4, 89 (2008), DOI: 10.1111/j.1574-6968.2007.01012.x

26. A. Miguel, V. R. Kaveh, M. Jie, H. Guogang, G. Ren Robert and P. Allaker, International Journal of Antimicrobial Agents, 40, 2 135(2012), DOI: 10.1016/j.ijantimicag.2012.04.012.

27. P. Vanathi , P. Rajiv , S. Narendhran , S. R. Pattanathu, K.S.M. Rahman and R. Venckatesh., Interdisciplinary Centre for Mathematical and Computational Modelling, 3,7(2014), DOI: 10.1016/j.matlet.2014.07.029 
RASĀYAN J. Chem.

Vol. 11 | No. 3 |1339 - 1348 | July - September | 2018

28. R. L. F. AJayalakshmy E. Orient J Chem, 31, 1 (2015) , DOI: 10.1128/AEM.02149-10

29. K. Żelechowska, BioTechnologia, 95, 2 150(2014), DOI: 10.13005/ojc/310105

30. A. Punnoose, K. Dodge, W. John, R. J. Chess, D. Wingett and Catherine Anders., ACS Sustainable Chem. Eng. 2, 1666(2014), DOI: 10.1021/sc500140x

31. H. Hei, H. Hong, R. Wang. L. Liu, Zhang.G., Soft Nanoscience Letters, 2,34(2012), DOI: 10.4236/snl.2012.23007

32. A. K. Singh, T. B. Tripathi, N. Pandey, D. P. Singh, D.Tripathi, O. N. Srivastava, Free Radical Biology and Medicine, 65, 217(2013), DOI: 10.1016/j.freeradbiomed.2013.06.006

33. D. Dhanasekaran, R.Thangaraj, Asian Pac. J. Trop. Dis., 3(3), 174(2013) , DOI: 10.1016/S22221808(13)60035-3

[RJC-2009/2017] 